\title{
The relationship among androgens, insulin resistance and ghrelin polymorphisms in post-adolescent male patients with severe acne vulgaris
}

\author{
Suzan Demir Pektas ${ }^{1}$, Nese Cinar², Deniz Demircioglu Duman ${ }^{3}$, Ahmet Kara ${ }^{4}$, Janserey Batu ${ }^{5}$, Sevim Karakas-Celik ${ }^{6}$, \\ Duygu Yazgan Aksoy ${ }^{7}$
}

\author{
${ }^{1}$ Department of Dermatology, Faculty of Medicine, Mugla Sitki Kocman University, Mugla, Turkey \\ 2Department of Endocrinology and Metabolic Diseases, Faculty of Medicine, Mugla Sitki Kocman University, Mugla, Turkey \\ ${ }^{3}$ Department of Dermatology, Acibadem University, Istanbul, Turkey \\ ${ }^{4}$ Department of Family Medicine, Faculty of Medicine, Mugla Sitki Kocman University, Mugla, Turkey \\ ${ }^{5}$ Department of Biochemistry, SYNLAB, Ankara, Turkey \\ ${ }^{6}$ Department of Molecular Biology and Genetic, Faculty of Science, Bulent Ecevit University, Zonguldak, Turkey \\ ${ }^{7}$ Department of Internal Medicine, Acibadem University, Istanbul, Turkey
}

Adv Dermatol Allergol 2020; XXXVII (5): 800-809

DOI: https://doi.org/10.5114/ada.2020.100492

\begin{abstract}
Introduction: Ghrelin has anti-inflammatory and immunomodulatory activities. Data about the role of ghrelin and ghrelin polymorphisms in the development of acne vulgaris in post-adolescent male patients are limited.

Aim: To evaluate the role of serum androgens, insulin resistance, ghrelin and ghrelin polymorphisms in severe acne vulgaris.

Material and methods: Thirty-five post-adolescent male patients with a mean age of $28.0 \pm 5.4$ years and 33 ageand BMI-matched controls were enrolled. Serum androgens, lipids, insulin sensitivity parameters and ghrelin levels were determined. The PCR method was used for GHRL polymorphisms (rs27647, rs696217 and rs34911341 genotypes).

Results: Patients had similar anthropometric measures to controls, except a significantly higher WHR in patients $(0.92 \pm 0.06$ vs. $0.86 \pm 0.08, p<0.05)$. Also, FPG, HOMA-IR values, lipid profile and serum androgen levels were similar. Interestingly, patients had significantly lower ghrelin levels than controls ( $4.5 \pm 5.8 \mathrm{vs} .101 .2 \pm 86.5 \mathrm{pg} / \mathrm{ml}, p<0.001)$. The frequencies of rs696217 and rs34911341 genotypes were similar whereas the distribution of rs27647 alleles was significantly different between the groups ( $p<0.05)$. GA and GG genotypes of GHRL rs 27647 polymorphism indicated an increased risk of developing acne vulgaris ( $\mathrm{OR}=11.156,95 \% \mathrm{Cl}: 2.864-43.464, \mathrm{OR}=5.312,95 \% \mathrm{Cl}$ : 1.269-22.244, respectively; $p<0.05$ ). Patients with rs27647-AA polymorphism had significantly lower GAGS scores than other groups (AA genotype $6.7 \pm 14.1$ vs. GA genotype $24.6 \pm 15.7$ and GG genotype $19.4 \pm 17.9, p<0.001$ ). None of the polymorphisms had a significant effect on metabolic parameters, insulin sensitivity and serum ghrelin levels. Conclusions: Decreased ghrelin levels and GA and GG genotypes of GHRL gene rs27647 polymorphism may have a role in the pathogenesis of acne vulgaris.
\end{abstract}

Key words: acne vulgaris, insulin resistance, ghrelin, ghrelin polymorphisms, post-adolescent.

\section{Introduction}

Acne is a chronic inflammatory disorder with papules, pustules, nodules and cysts in the pilosebaceous units of the face, chest and back [1, 2]. During adolescence, $85 \%$ of teenagers are affected by this disorder. However, nowadays, many lifestyle factors such as Western type diet [3], obesity, occupation, stress [4] lead to the increase in the incidence of acne vulgaris in patients after the adolescence period [5]. Multiple etiologic factors such as increased sebum production, increased keratinocyte proliferation, colonization of the intrafollicular duct by Cutibacterium acnes (formerly Propionibacterium acnes), chronic inflammation, play a role in the development of acne vulgaris [6,7]. The sebaceous gland is

Address for correspondence: Suzan Demir Pektas MD, Department of Dermatology, Faculty of Medicine, Mugla Sitki Kocman University, 48000 Mugla, Turkey, phone: +90 252211 5219, fax: +90 312 3116768, e-mail: suzandpektas@gmail.com Received: 11.01.2019, accepted: 1.04.2019. 
the major site of steroid synthesis in human skin. The sebaceous gland has all necessary enzymes for the synthesis and metabolism of androgen from cholesterol to $5 \alpha$-dihydrotestosterone (DHT). Moreover, expression of androgen receptors (AR), estrogen receptors especially $E R \alpha$ and progesterone receptors have been shown in the previous studies $[8,9]$. Androgens increase the activity of sebaceous glands leading to increased sebum production and stimulate keratinocyte proliferation [10].

In the recent epidemiologic studies, high-glycaemicload diets are shown to promote the development or exacerbation of acne vulgaris [11, 12]. It is thought that high-glycaemic-load diets induce hyperinsulinemia, which enhances the synthesis of androgens and insulinlike growth factor-1 (IGF-1) [13]. IGF-1 induces keratinocyte proliferation, sebocyte proliferation and sebum production [13]. Nevertheless, many disorders associated with hyperandrogenemia and insulin resistance such as polycystic ovary syndrome and hyperandrogenism-insulin resistance-acanthosis nigricans (HAIR-AN) syndrome are the classic examples of endocrinological disorders closely associated with acne [14].

Ghrelin is a 28-aa acylated polypeptide hormone, secreted from the stomach with an orexigenic effect. It stimulates appetite, fat deposition and gluconeogenesis [15]. In obese patients, lower ghrelin levels were reported compared to controls, suggesting a relationship between ghrelin and metabolic disorders [16, 17]. Nevertheless, a negative correlation between levels of total ghrelin and number of components of metabolic syndrome was reported in the OPERA study [18]. Ghrelin is also reported to be the main endogenous ligand for growth hormone secretion [19]. Moreover, it has anti-inflammatory and immunomodulatory actions [20]. In a recently reported study, a strong ghrelin immunoreactivity was found in the hair follicles and sebaceous glands in the sections of human skin, suggesting a possible role of ghrelin in the pathogenesis of acne [21]. However, there are few studies in the literature regarding this issue [21-23].

The gene encoding ghrelin is the GHRL gene which is located on chromosome 3p26-25 and contains four exons and three introns. To date, at least 263 single nucleotide polymorphisms (SNPS) in the GHRL gene have been reported. GHRL SNP rs27647 is located in the promoter region. GHRL rs696217 polymorphism is characterized by a $G$ to $T$ substitution resulting in a leucine (Leu) to methionine (Met) exchange at position 72 in exon 2 of the coding region of the GHRL gene, whereas the rs34911341 polymorphism is characterized by a $C$ to $T$ transition causing an arginine (Arg) to glutamine (GIn) exchange at position 51 in exon 2. In addition, these genetic variations in the GHRL gene may affect the expression and function of ghrelin protein and modulate the manifestation of different disorders $[18,24]$. In the literature, these GHRL polymorphisms are reported to be associated with obesity [25], metabolic syndrome [26, 27], type 2 diabe- tes [28] and breast cancer [29]. To date, there have been no data in the literature concerning the relationship between GHRL polymorphisms and the risk of acne vulgaris. Although there are many studies to find out the pathogenesis of acne in female patients with acne vulgaris [3, 30], there are few studies conducted on post-adolescent male patients with acne [31, 32].

\section{Aim}

In this study, we aimed to find out the role of serum androgens, insulin resistance, ghrelin and GHRL polymorphisms (rs27647, rs696217 and rs34911341 genotypes) on the development of acne in post-adolescent male patients with acne vulgaris.

\section{Material and methods}

\section{Study population and design}

This study was approved by the Ethics Committee for Clinical Studies of the Acıbadem University School of Medicine (Number 2017-7/11) and was performed in accordance with the guidelines of the Declaration of Helsinki and written informed consent was obtained from all patients and controls before the study.

We included 35 post-adolescent male patients with severe acne vulgaris without first-degree relatives with acne vulgaris and 33 age- and gender-matched healthy volunteers. Acne vulgaris patients who were admitted to the Department of Dermatology at Mugla Sitki Kocman University Training and Research Hospital between January and July 2017 were enrolled in the study.

Post-adolescent male patients with severe acne vulgaris who were older than 18 years and received no systemic treatment for acne in the last 6 months and healthy volunteers were included in the study. The exclusion criteria are female gender and presence of malignancies, active liver disease, renal disorders, infections, alcohol use, and medication use for conditions. Thirty-five acne patients were evaluated for the severity of acne by the dermatologist using the Global Acne Grading Scale (GAGS) [33]. It divides the face, chest and back into 6 sub-areas and evaluates both the distribution of the acne and the type of lesions. The total score is classified as mild (1-18), moderate (19-30), severe (31-38) and very severe (38-44).

Demographic features, anthropometric measures and blood pressure values were recorded. Duration of the acne vulgaris was obtained by self-report. Age, weight, height, body mass index (BMl; weight (kilograms)/height (meters) $)^{2}$ and waist circumference (WC) and hip circumference (waist: midway between the lower rib margin and the iliac crest, hip: widest circumference over the great trochanters) were evaluated at baseline. Fasting plasma glucose (FPG), fasting insulin and lipid profile (total cholesterol, triglycerides (TG), high density lipoprotein 
Table 1. PCR-RFLP conditions of the polymorphisms of the ghrelin genes

\begin{tabular}{cccccc}
\hline Gene & Polymorphism & Primers & $\begin{array}{c}\text { Temperature of } \\
\text { annealing }\left[{ }^{\circ} \mathrm{C}\right]\end{array}$ & $\begin{array}{c}\text { Restriction } \\
\text { endonuclease }\end{array}$ & PCR products \\
\hline Ghrelin & rs27647 & P1 & 65 & Dral & $\begin{array}{c}\text { G allele: } 664 \text { and } 265 \text { bp } \\
\text { A allele: } 929 \text { bp }\end{array}$ \\
\cline { 2 - 5 } & P2 & P3 & 53 & Sacl & $\begin{array}{c}\text { G allele: } 455 \text { and } 163 \mathrm{bp} \\
\text { A allele: } 618 \mathrm{bp}\end{array}$ \\
\hline & rs34911341 & P4 & & Bsr-I & $\begin{array}{c}\text { C allele: } 517 \text { and } 101 \mathrm{bp} \\
\text { A allele: } 618 \mathrm{bp}\end{array}$ \\
\hline
\end{tabular}

P1-5'-CACAGCAACAAAGCTGCACC-3', P2 - 5'-AAGTCCAGCCAGAGCATGCC-3', P3-5'-GCTGGGCTCCTACCTGAGC-3', P4 - 5'-GGACCCTGTTCACTGCCAC-3'.

cholesterol (HDL-C), low density lipoprotein cholesterol (LDL-C)) were measured. Homeostatic model assessment of insulin resistance $(\mathrm{HOMA}-\mathrm{IR}=$ (fasting insulin $(\mu \mathrm{U} / \mathrm{ml})$ $\times$ FPG $(\mathrm{mmol} / \mathrm{l})) / 22.5)$ and LDL-C (LDL-C = total cholesterol - (HDL-C + (TG/5))) were calculated as previously described [34].

The patients with HOMA-IR values > 2.7 were accepted as insulin-resistant. In all subjects, serum concentrations of luteinizing hormone (LH), follicle stimulating hormone (FSH), sex hormone binding globulin (SHBG), dehydroepiandrosterone sulfate (DHEAS) and prolactin were measured. Free androgen index was calculated using the following formula $(\mathrm{FAI}=(\mathrm{TT} / \mathrm{SHBG}) \times$ 100).

Also, serum fasting ghrelin levels and GHRL gene polymorphisms (rs27647, rs696217, rs34911341) were evaluated.

\section{Assays}

Venous blood samples were obtained from the volunteers after at least $8 \mathrm{~h}$ fasting in the morning. After that the blood samples were centrifuged at $3600 \mathrm{rpm}$ for $10 \mathrm{~min}$. The obtained serum was stored at $-80^{\circ} \mathrm{C}$ and all samples were evaluated at the same time. Glucose was measured with Cobas 6000 Analyzer (Roche Diagnostics, USA) by using the UV hexokinase method. Insulin was measured with the Cobas 6000 Analyzer (Roche Diagnostics, USA) immunoassay device by using the chemiluminescence immunoassay method. Triglyceride and total cholesterol levels were determined with the enzymatic colorimetric assay. HDL-C was determined with the homogenous enzymatic colorimetric assay. Serum LH, FSH, total testosterone, DHEAS, prolactin and SHBG were measured by electrochemiluminescence immunoassay on Modular Analytics E170 (Roche Diagnostics, Tokyo, Japan). Measurement of acylated ghrelin in plasma was performed using a double-antibody sandwich enzyme immunoassay (Human Acylated Ghrelin ELISA, BioVendor Laboratory Medicine, Inc., Modrice, Czech Republic, Calibration Range 1.96-250 pg/ml) with Intra-assay (WithinRun) CV $=8.0 \%\left(20 \mathrm{~h} \mathrm{at}+4^{\circ} \mathrm{C}\right) \mathrm{CV}=7.0 \%$ ( $3 \mathrm{~h}$ at RT $)$ and Inter-assay (Run-to-Run) CV $=8.4 \%\left(20 \mathrm{~h}\right.$ at $\left.+4^{\circ} \mathrm{C}\right) \mathrm{CV}=$ 8.2\% (3 $h$ at RT).

\section{Genotyping}

After written, informed consent was obtained, venous blood samples were collected into vacutainer plastic tubes containing sodium/potassium EDTA. DNA was extracted from Genejet Genomic DNA purification kit (Thermo Catalog number: K0721). We analysed rs27647 (-604G/A) polymorphism in the promoter region and rs34911341 (Arg51Gln 346G/A), rs696217 (Leu72Met (408C/A) polymorphisms in exon 2 of the coding region of the GHRL gene.

Amplification of the target DNA in the promoter region was carried out using PCR condition at Table 1 . The product was detected by electrophoresis in a 1.5\% agarose gel and visualized under ultraviolet light after staining with ethidium bromide.

\section{Statistical analysis}

To complete statistical assessments, the Statistical Package for Social Sciences (SPSS) software for Windows 18 (IBM SPSS Inc., Chicago, USA) was used. Data were shown as mean \pm standard deviation (SD). A $\chi^{2}$ or Fisher exact test was used to evaluate categorical variables. The mean differences of continuous variables with normal distribution between patients with acne and control groups were compared with an independent sample student $t$-test and for those with non-normal distribution were compared with the Mann-Whitney $U$ test when applicable. The allelic and genotypic frequencies of the polymorphisms were calculated both in the cases and healthy subjects. The association between GHRL polymorphisms and acne vulgaris was modelled through binary logistic regression analysis and odds ratio (OR) and 95\% confidence interval $(95 \% \mathrm{Cl})$ were calculated to compare the acne vulgaris risk around the genotype. The comparisons of patients in the groups of GHRL rs27647 gene genotypes (AA-GA-GG) and GHRL rs696217 gene genotypes (CC-AA-CA) were performed by one-way analysis of variance (ANOVA) and post hoc Tukey test for dual-wise comparisons for normally distributed parameters, and Kruskal-Wallis one-way ANOVA and Mann-Whitney test for dual-wise comparisons for parameters with skewed distribution. A p-value less than 0.05 was considered to be statistically significant. 


\section{Results}

Basal demographic features of the postadolescent acne patients and controls

Thirty-five post-adolescent male patients with acne vulgaris with a mean age of $28.0 \pm 5.4$ years and 33 ageand $\mathrm{BMI}$-matched control subjects were enrolled in the study. Mean duration of the disease was $6.5 \pm 2.7$ years. Mean GAGS of the patients was $34.4 \pm 3.0$.

The comparison of demographic features, anthropometric measures, laboratory findings and blood pressure values of the participants are summarized in Table 2. Patients with acne vulgaris and healthy subjects had similar anthropometric measures. Interestingly, the waist to hip ratio (WHR) of the acne vulgaris patients was significantly higher compared to controls $(p<0.05)$. There was no significant difference in systolic blood pressure (SBP) and diastolic blood pressure (DBP) values between the groups. Both groups had similar FPG, insulin, HOMA-IR, TG and HDL-C levels whereas patients with acne vulgaris had significantly lower LDL-C levels compared to controls $(p<0.05)$. Regarding serum androgen levels, there was no significant difference between the groups. Interestingly, patients with acne vulgaris had significantly lower serum ghrelin levels compared to the control group ( $p<$ 0.001).

\section{Distribution of GHRL polymorphisms in post- adolescent acne patients and controls}

The frequencies of the genotypes of the GHRL genes in the participants are shown in Table 3. The patient group showed similar distribution with the control group in rs34911341 and rs696217 polymorphisms of the GHRL gene. On the other hand, the patients with acne vulgaris had significantly different distribution of the frequencies of the rs27647 polymorphism $(p<0.05)$. For GHRL rs27647 polymorphism, GA and GG genotype indicated an increased risk of developing acne vulgaris $(\mathrm{OR}=11.156,95 \% \mathrm{Cl}: 2.864-43.464, \mathrm{OR}=5.312,95 \% \mathrm{Cl}$ : 1.269-22.244, respectively; Table 3).

Table 2. Comparison of the clinical characteristics and biochemical parameters of the control and post-adolescent male patients with acne vulgaris

\begin{tabular}{|c|c|c|c|}
\hline Parameter & $\begin{array}{l}\text { Control group } \\
\quad(n=33)\end{array}$ & $\begin{array}{l}\text { Acne vulgaris group } \\
\qquad(n=35)\end{array}$ & $P$-value \\
\hline Age [years] & $28.4 \pm 4.9$ & $28.0 \pm 5.4$ & NS \\
\hline Weight [kg] & $72.8 \pm 6.8$ & $73.7 \pm 7.5$ & NS \\
\hline $\mathrm{BMI}\left[\mathrm{kg} / \mathrm{m}^{2}\right]$ & $23.9 \pm 2.1$ & $23.7 \pm 2.2$ & NS \\
\hline WHR & $0.86 \pm 0.08$ & $0.92 \pm 0.06$ & $<0.05$ \\
\hline Systolic BP [mm Hg] & $117.1 \pm 6.8$ & $112.8 \pm 10.4$ & NS \\
\hline Diastolic BP [mm Hg] & $73.7 \pm 6.9$ & $75.5 \pm 6.6$ & NS \\
\hline $\mathrm{FPG}[\mathrm{mg} / \mathrm{dl}]$ & $87.8 \pm 11.5$ & $88.1 \pm 7.1$ & NS \\
\hline Basal insulin [mU/l] & $10.1 \pm 5.6$ & $11.8 \pm 6.8$ & NS \\
\hline HOMA-IR & $2.2 \pm 1.3$ & $2.5 \pm 1.5$ & NS \\
\hline LDL-C [mg/dl] & $108.3 \pm 34.7$ & $87.6 \pm 28.4$ & $<0.05$ \\
\hline Triglyceride [mg/dl] & $128 \pm 66.3$ & $111.8 \pm 50.4$ & NS \\
\hline $\mathrm{TC}[\mathrm{mg} / \mathrm{dl}]$ & $184.6 \pm 40.3$ & $160 \pm 33.7$ & $<0.05$ \\
\hline $\mathrm{HDL}-\mathrm{C}[\mathrm{mg} / \mathrm{dl}]$ & $54.1 \pm 14.4$ & $55.8 \pm 17.3$ & NS \\
\hline $\mathrm{FSH}[\mathrm{mlU} / \mathrm{ml}]$ & $5.7 \pm 1.4$ & $3.7 \pm 1.7$ & $<0.001$ \\
\hline $\mathrm{LH}[\mathrm{mlU} / \mathrm{ml}]$ & $5.5 \pm 1.4$ & $5.1 \pm 1.8$ & NS \\
\hline Total testosterone $[\mathrm{ng} / \mathrm{ml}]$ & $4.9 \pm 1.6$ & $5.3 \pm 1.9$ & NS \\
\hline SHBG [nmol/l] & $29 \pm 9.7$ & $30.7 \pm 16.4$ & NS \\
\hline FAl & $19.2 \pm 10.6$ & $20.8 \pm 15.6$ & NS \\
\hline DHEAS $[\mu \mathrm{g} / \mathrm{dl}]$ & $297.5 \pm 46.3$ & $336.7 \pm 125.7$ & NS \\
\hline Ghrelin [pg/ml] & $101.2 \pm 86.5$ & $4.5 \pm 5.8$ & $<0.001$ \\
\hline
\end{tabular}

Data were presented as mean \pm SD, The $p$-values $<0.05$ were assessed as statistically significant. $N$ - number of volunteers, NS - non-significant, BMI - body mass index. WHR - waist to hip ratio, BP-blood pressure, FPG - fasting plasma glucose, HOMA-IR - homeostatic model assessment of insulin resistance, LDL-C - low-density lipoprotein cholesterol, TC - total cholesterol, HDL-C - high-density lipoprotein cholesterol, LH - luteinizing hormone, FSH-follicle stimulating hormone, SHBG - sex hormone binding globulin, FAI - free androgen index, DHEAS - dehydroepiandrosterone sulphate. 
Table 3. Genotype and allele frequencies of ghrelin gene variants in post-adolescent male patients with acne vulgaris and healthy controls

\begin{tabular}{lcccc}
\hline $\begin{array}{l}\text { Ghrelin gene } \\
\text { rs27647: }\end{array}$ & $\begin{array}{c}\text { Controls } \\
n(\%)\end{array}$ & $\begin{array}{c}\text { Acne vulgaris } \\
n(\%)\end{array}$ & OR (95\% Cl) & P-value \\
\hline AA & $17(51.5)$ & $4(11.4)$ & Reference & 0.002 \\
\hline GA & $8(24.2)$ & $21(60)$ & $11.156(2.864-43.464)$ & 0.001 \\
\hline GG & $8(24.2)$ & $10(28.6)$ & $5.312(1.269-22.244)$ & 0.022 \\
\hline rs34911341: & & & & \\
\hline GG & $33(100)$ & $35(100)$ & & 0.817 \\
\hline rs696217: & & & Reference & 0.716 \\
\hline CC & $23(69.6)$ & $24(68.6)$ & $0.767(0.183-3.216)$ & 0.653 \\
\hline AA & $5(15.2)$ & $4(14.4)$ & $1.342(0.372-4.836)$ & \\
\hline CA & $5(15.2)$ & $7(20.0)$ & & \\
\hline
\end{tabular}

The $p$-values $<0.05$ were considered as statistically significant.

\section{Clinical and biochemical characteristics of the post-adolescent patients with acne vulgaris according to GHRL gene polymorphisms}

Table 4 summarizes the comparison of the clinical characteristics and biochemical parameters of the alleles of GHRL rs27647 gene genotype in acne vulgaris patients. Mean disease duration of the GA allele group of the patients was significantly shorter than in the GG allele group $(5.4 \pm 1.7$ years vs. $8.5 \pm 3.1$ years, $p<0.007)$ The patients with rs27647 gene-AA genotype had significantly lower GAGS than other patients with GA and GG genotypes ( $p<0.001)$. Regarding anthropometric measures, blood pressure values, insulin sensitivity values and lipid profile, there was no significant difference among the groups. Moreover, the groups had similar serum androgen and ghrelin levels.

Table 5 summarizes the comparison of the clinical characteristics and biochemical parameters of the alleles of GHRL rs696217 genotype in patients with acne vulgaris. There was no significant difference in mean disease duration and GAGS scores among the groups. The groups displayed similar anthropometric measures, insulin sensitivity parameters, lipid profile and androgen levels. Only, serum DHEAS levels in patients with rs696217 gene-AA genotype were significantly higher than in other groups with CC and CA alleles $(p<0.05)$. Moreover, the groups showed similar serum ghrelin levels.

\section{Discussion}

Acne vulgaris is a chronic inflammatory dermatosis and hyperinsulinemia and ghrelin might have a role in the development of acne. In this study, we revealed that post-adolescent male patients with acne vulgaris had similar anthropometric measures to controls, except higher WHR in patients. The patients with acne vulgaris had similar FPG, insulin levels and lipid profile to healthy subjects. There was no significant difference in serum androgen levels between the groups. Interestingly, male patients with acne vulgaris had significantly lower levels of ghrelin compared to controls. Regarding the distribution of GHRL gene polymorphisms (rs27647, rs696217 and rs34911341 genotypes), there was no difference in the frequencies of rs696217 and rs34911341 genotypes between the groups whereas the distribution of rs 27647 alleles was significantly different between the groups. GA and GG genotypes of GHRL gene rs27647 polymorphism are associated with an increased risk of acne vulgaris development and the severity of acne in post-adolescent male patients. None of the polymorphisms had a significant effect on metabolic parameters, insulin sensitivity or serum ghrelin levels in patients with acne vulgaris.

Most of the studies evaluating the association between androgens and acne vulgaris are conducted in women, especially with polycystic ovary syndrome (PCOS); there are few studies in the literature about this subject in male patients [35-38]. The plasma values of serum androgens for both groups of patients did not differ significantly from those of the age-matched control groups in some studies [1, 2, 32] whereas serum total testosterone, androstenedione and DHEAS levels were found to be significantly elevated in severe acne male patients compared to mild- and moderate acne patients $[3,38]$. In our study, we evaluated serum androgen levels in post-adolescent acne patients and found comparable serum androgen levels to healthy subjects, in accordance with many studies in the literature. Since the majority of the patients with acne vulgaris have normal androgen levels, probably increased peripheral conversion of androgens at the receptor site is the main mechanism [39].

Many metabolic disorders such as dyslipidaemia, obesity, metabolic syndrome and PCOS show comorbidity 
Table 4. Comparison of the clinical characteristics and biochemical parameters of the alleles of ghrelin rs27647 gene genotype in the post-adolescent patients with acne vulgaris

\begin{tabular}{|c|c|c|c|c|}
\hline Parameter & $\mathrm{AA}(n=4)$ & $\mathrm{GA}(n=21)$ & GG $(n=10)$ & $P$-value \\
\hline Age [years] & $25.0 \pm 3.2$ & $27.9 \pm 5.6$ & $29.4 \pm 5.8$ & NS \\
\hline Disease duration [years] & $6.7 \pm 3.5$ & $5.4 \pm 1.7^{\mathrm{a}}$ & $8.5 \pm 3.1$ & $<0.007$ \\
\hline GAGS & $6.7 \pm 14.1^{\mathrm{b}, \mathrm{c}}$ & $24.6 \pm 15.7$ & $19.4 \pm 17.9$ & 0.001 \\
\hline Weight [kg] & $70 \pm 7.1$ & $74.6 \pm 6.9$ & $73.3 \pm 9.1$ & NS \\
\hline BMI $\left[\mathrm{kg} / \mathrm{m}^{2}\right]$ & $22.4 \pm 2.9$ & $23.9 \pm 2.1$ & $23.8 \pm 2.6$ & NS \\
\hline WHR & $0.8 \pm 0.0$ & $0.9 \pm 0.0$ & $0.9 \pm 0.0$ & NS \\
\hline Systolic BP [mm Hg] & $110 \pm 8.1$ & $111.4 \pm 11.5$ & $117 \pm 8.2$ & NS \\
\hline Diastolic BP [mm Hg] & $71.2 \pm 2.5$ & $75.2 \pm 7.4$ & $78 \pm 4.8$ & NS \\
\hline FPG [mg/dl] & $87.2 \pm 9$ & $89 \pm 6.5$ & $86.6 \pm 8$ & NS \\
\hline Basal insulin [mU/l] & $12.7 \pm 12.5$ & $12.1 \pm 6.5$ & $10.7 \pm 5.3$ & NS \\
\hline HOMA-IR & $2.9 \pm 3.1$ & $2.6 \pm 1.4$ & $2.3 \pm 1.1$ & NS \\
\hline LDL-C [mg/dl] & $21.7 \pm 10.8$ & $29 \pm 6.3$ & $30.6 \pm 9.7$ & NS \\
\hline Triglyceride [mg/dl] & $75 \pm 32$ & $124 \pm 56.4$ & $101 \pm 33.6$ & NS \\
\hline $\mathrm{TC}[\mathrm{mg} / \mathrm{dl}]$ & $184.2 \pm 40.2$ & $157.2 \pm 29.9$ & $156 \pm 38.5$ & NS \\
\hline $\mathrm{HDL}-\mathrm{C}[\mathrm{mg} / \mathrm{dl}]$ & $68.7 \pm 27.6$ & $53 \pm 14.8$ & $56.6 \pm 17.2$ & NS \\
\hline $\mathrm{FSH}[\mathrm{mlU} / \mathrm{ml}]$ & $2.8 \pm 1.8$ & $3.4 \pm 1.4$ & $4.5 \pm 2$ & NS \\
\hline LH [mlU/ml] & $6.4 \pm 0.5$ & $4.9 \pm 1.8$ & $4.8 \pm 2$ & NS \\
\hline Total testosterone [ng/ml] & $7.1 \pm 2.3$ & $4.8 \pm 1.7$ & $5.6 \pm 1.7$ & NS \\
\hline SHBG [nmol/l] & $47 \pm 36.5$ & $29.9 \pm 11.8$ & $25.8 \pm 11.1$ & NS \\
\hline FAl & $18.6 \pm 6$ & $16.9 \pm 4.9$ & $29.8 \pm 26.9$ & NS \\
\hline DHEAS $[\mu \mathrm{g} / \mathrm{dl}]$ & $479.2 \pm 197$ & $312.9 \pm 110.8$ & $329.9 \pm 95.2$ & NS \\
\hline Ghrelin [pg/ml] & $2.9 \pm 0.6$ & $4.6 \pm 5.5$ & $4.8 \pm 7.6$ & NS \\
\hline
\end{tabular}

Data were presented as mean \pm SD, The $p$-values $<0.05$ were assessed as statistically significant. $N$ - number of volunteers, NS - non-significant, GAGS - global acne grading score, BMI - body mass index, WHR - waist to hip ratio, BP-blood pressure, FPG - fasting plasma glucose, HOMA-IR - homeostatic model assessment of insulin resistance, LDL-C - low-density lipoprotein cholesterol, TC - total cholesterol, HDL-C - high-density lipoprotein cholesterol, LH - luteinizing hormone, FSH - follicle stimulating hormone, SHBG - sex hormone binding globulin, FAI - free androgen index, DHEAS - dehydroepiandrosterone sulphate. ${ }^{a} p$ $<0.05$; GA allele group vs. GG allele group. ${ }^{b} p<0.05$; AA allele group vs. GG allele group. ${ }^{c} p<0.05$; $A A$ allele group vs. GA allele group.

with acne [40-43]. Nevertheless, in a large cross-sectional study including 3207 patients with acne vulgaris and 6412 age- and sex-matched control patients, acne vulgaris was found to be significantly associated with metabolic syndrome $(\mathrm{OR}=1.61,95 \% \mathrm{Cl}: 1.36-1.89)$, diabetes $(\mathrm{OR}=1.41,95 \% \mathrm{Cl}: 1.19-1.66)$, obesity $(\mathrm{OR}=1.71,95 \% \mathrm{Cl}$ : $1.53-1.91)$, hyperlipidaemia (OR $=1.14,95 \% \mathrm{Cl}: 1.02-1.28)$ and hypertension ( $\mathrm{OR}=1.19,95 \% \mathrm{Cl}: 1.03-1.38)$ [42]. The prevalence of acne is about $70 \%$ in PCOS, which is a disorder with increased peripheral insulin resistance and hyperinsulinemia. The data about the relationship between acne and metabolic profile in male patients is limited in the literature [31, 32, 44]. In a study including 35 male and female patients with a mean age of 30.8 years, no significant differences were observed in FPG, insulin, lipid and HOMA-IR values between patients with acne and controls [44], in line with our study. In addition, Kaymak et al. failed to show any significant differences in FPG, fasting insulin levels and HOMA-IR values in 30 female and 19 male acne vulgaris patients with a mean age of
21.7 [45]. In another study including 26 post-adolescent women with severe acne, serum androgens and insulin sensitivity markers were found to be similar to controls [46]. All these studies included both types of sexes or only women, whereas we evaluated exclusively male patients in our study. Contradictory to our results, Del Prete et al. reported higher BMI, WC, WHR, SBP, DBP, basal and OGTT 120 min. insulin, basal glucose levels and HOMA-IR values and lower HDL-cholesterol levels in patients with acne compared to controls [32]. In this study, the age of patients was 15-26 years including both adolescent and post-adolescent patients. We only found higher WHR in acne patients compared to healthy subjects. In a study including 100 male post-adolescent acne patients, mean BMI, SDP, DBP, FPG levels and HOMA-IR values were reported to be significantly higher in patients compared to controls though all these parameters were within normal limits [31]. The prevalence of insulin resistance was also found to be significantly higher in patients compared to controls ( $22 \%$ vs. $11 \%, p=0.03$ ) whereas there was 
Table 5. Comparison of the clinical characteristics and biochemical parameters of the alleles of ghrelin rs696217 gene genotype in the post-adolescent male patients with acne vulgaris

\begin{tabular}{|c|c|c|c|c|}
\hline Parameter & $\mathrm{CC}(n=24)$ & $\mathrm{AA}(n=4)$ & $\mathrm{CA}(n=7)$ & $P$-value \\
\hline Age [years] & $28.0 \pm 4.9$ & $23.2 \pm 2.6$ & $30.8 \pm 6.9$ & NS \\
\hline Disease duration [years] & $6.5 \pm 2.8$ & $5.5 \pm 2.5$ & $6.8 \pm 3.1$ & NS \\
\hline GAGS & $17.5 \pm 17.5$ & $15.4 \pm 18.4$ & $20.0 \pm 17.8$ & NS \\
\hline Weight [kg] & $73.6 \pm 8.1$ & $72 \pm 4.5$ & $75 \pm 7.3$ & NS \\
\hline BMI $\left[\mathrm{kg} / \mathrm{m}^{2}\right]$ & $24 \pm 2.3$ & $23.1 \pm 0.8$ & $23 \pm 2.5$ & NS \\
\hline WHR & $0.9 \pm 0.0$ & $0.9 \pm 0.1$ & $0.9 \pm 0.0$ & NS \\
\hline Systolic BP [mm Hg] & $112 \pm 11.7$ & $115 \pm 5.7$ & $111.2 \pm 7.8$ & NS \\
\hline Diastolic BP [mm Hg] & $75 \pm 6.9$ & $76.2 \pm 7.5$ & $77.1 \pm 5.6$ & NS \\
\hline FPG [mg/dl] & $88.4 \pm 6.8$ & $87.5 \pm 7.8$ & $87.5 \pm 8.8$ & NS \\
\hline Basal insulin [mU/l] & $11.3 \pm 5.7$ & $6.8 \pm 2.9$ & $16.2 \pm 9.7$ & NS \\
\hline HOMA-IR & $2.5 \pm 1.3$ & $1.5 \pm 0.6$ & $3.5 \pm 2.1$ & NS \\
\hline LDL-C [mg/dl] & $81 \pm 29.6$ & $114.2 \pm 9.9$ & $94.9 \pm 21.5$ & NS \\
\hline Triglyceride [mg/dl] & $122.6 \pm 53.6$ & $85.5 \pm 45.7$ & $90.1 \pm 29.4$ & NS \\
\hline $\mathrm{TC}[\mathrm{mg} / \mathrm{dl}]$ & $152 \pm 32.6$ & $181.7 \pm 31$ & $174.8 . \pm 32.8$ & NS \\
\hline $\mathrm{HDL}-\mathrm{C}[\mathrm{mg} / \mathrm{dl}]$ & $53.7 \pm 14.9$ & $59.2 \pm 20.8$ & $61.2 \pm 23.7$ & NS \\
\hline $\mathrm{FSH}[\mathrm{mlU} / \mathrm{ml}]$ & $3.4 \pm 1.5$ & $4.3 \pm 2.8$ & $4 \pm 1.7$ & NS \\
\hline $\mathrm{LH}[\mathrm{mlU} / \mathrm{ml}]$ & $4.9 \pm 1.9$ & $6.6 \pm 0.3$ & $4.5 \pm 1.7$ & NS \\
\hline Total testosterone $[\mathrm{ng} / \mathrm{ml}]$ & $5.1 \pm 1.6$ & $6.4 \pm 2.9$ & $5.3 \pm 2.3$ & NS \\
\hline SHBG [nmol/l] & $28.3 \pm 11.2$ & $44 \pm 38.3$ & $31.2 \pm 13.3$ & NS \\
\hline FAl & $21.4 \pm 17.3$ & $18.1 \pm 6.7$ & $20.1 \pm 14$ & NS \\
\hline DHEAS $[\mu \mathrm{g} / \mathrm{dl}]$ & $338.1 \pm 86.3^{\mathrm{a}}$ & $522.2 \pm 165.2$ & $226.3 \pm 101.1^{\mathrm{b}}$ & $<0.05$ \\
\hline Ghrelin [pg/ml] & $4.8 \pm 6.7$ & $2.5 \pm 1.9$ & $4.4 \pm 3.4$ & NS \\
\hline
\end{tabular}

Data were presented as mean \pm SD, The $p$-values $<0.05$ were assessed as statistically significant. N-number of volunteers, NS - non-significant, GAGS - global acne grading score, BMI - body mass index, WHR - waist to hip ratio, BP-blood pressure, FPG - fasting plasma glucose, HOMA-IR - homeostatic model assessment of insulin resistance, LDL-C - low-density lipoprotein cholesterol, TC - total cholesterol, HDL-C - high-density lipoprotein cholesterol, LH - luteinizing hormone, FSH - follicle stimulating hormone, SHBG - sex hormone binding globulin, FAl - free androgen index, DHEAS - dehydroepiandrosterone sulphate. ${ }^{a} p<0.05 ;$ CC allele group vs. AA allele group. ${ }^{b} p<0.05$; CC allele group vs. CA allele group.

no significant difference in the prevalence of metabolic syndrome between the groups [31]. The severity of acne was associated with BMI but not with insulin resistance or metabolic syndrome [31]. These controversial results might be due to the heterogeneity of the participants in the studies. Moreover, all these results cannot exclude the local interaction between insulin and the pilosebaceous unit.

Regarding the association between acne formation and ghrelin, the data are still inconclusive. Cicek et al. studied the ghrelin immunoreactivity by the immunohistochemistry method in the pilosebaceous unit and serum ghrelin levels in 30 acne vulgaris patients aged 18-26 years (15 M, 15 F) [21]. They demonstrated strong ghrelin immunoreactivity in the hair follicles and sebaceous glands [21]. The authors also found that the mean serum ghrelin levels in patients with acne vulgaris were significantly lower than in healthy subjects $(27.58 \pm 15.44 \mathrm{pg} /$ $\mathrm{ml}$ vs. $35.62 \pm 20.46 \mathrm{pg} / \mathrm{ml}, p=0.04$ ) [21], in line with our study. Although the prevalence of insulin resistance was significantly higher in patients with acne vulgaris, there was no significant difference in ghrelin levels between the patients with insulin resistance and without insulin resistance [21]. In a population-based study including 519 hypertensive patients, ghrelin concentrations were reported to be negatively associated with fasting insulin $(p<0.001)$, systolic $(p=0.026)$ and diastolic BP ( $p=0.018)$, and the prevalence of type 2 diabetes $(p=0.015)$ and insulin resistance $(p<0.001)$ in the multivariate regression analysis [47]. Moreover, PCOS patients were shown to have lower ghrelin levels compared to controls [48, 49] and low ghrelin levels were associated with insulin resistance [49]. Ozuguz et al. reported similar ghrelin levels in 30 acne vulgaris patients (17 F, $13 \mathrm{M}$ ) aged 18-25 years and controls [22]. Cemil et al. evaluated the treatment effect of isotretinoin on serum adiponectin, leptin and ghrelin levels in acne vulgaris patients ( $20 \mathrm{M}, 12 \mathrm{~F})$ and demonstrated that serum adiponectin and leptin levels increased significantly while serum ghrelin levels did not change [23]. In our study, we 
found significantly lower ghrelin levels in patients with acne vulgaris compared to controls despite similar insulin and HOMA-IR values. These results suggest that the decreased anti-inflammatory and anti-microbial effect of ghrelin may trigger inflammation and/or exacerbate the inflammatory process in the pathogenesis of acne vulgaris independent of insulin resistance. Nevertheless, in many studies [50, 51], it has been reported that in physiological concentrations, ghrelin shows bactericidal activity towards Cutibacterium acnes, which has a great role in the development of acne.

Ghrelin as an orexigenic hormone, the relationship between ghrelin and obesity, metabolic syndrome and the role of GHRL polymorphisms upon this issue are researched in several studies $[25,27,52,53]$. Rs696217 polymorphism was demonstrated to be associated with an increased risk of central obesity while rs27647genotype with a reduced risk [52]. Other studies however failed to show any significant association between metabolic syndrome components and ghrelin polymorphisms [53]. Moreover, a significant decreasing trend from Leu/ Leu to Leu/Met and to Met/Met homozygous subjects in triglycerides, fasting insulin and HOMA-IR values was reported in a study including 1420 subjects while a significant decrease in insulin and HOMA-IR values from CC to TC and TT genotypes of rs 27647 genotype was reported [54]. However, we failed to show any significant effect of these polymorphisms on metabolic parameters, insulin sensitivity markers and ghrelin levels in post-adolescent male patients with severe acne vulgaris.

In the literature, there are genome-wide association studies about acne including large number of patients $[55,56]$. He et al. included 1860 acne and 3660 healthy subjects of a Chinese Han population [55]. Three SNPs in two genome-wide significant susceptibility loci (1q24.2 and 11p11.2) containing genes related to androgen metabolism, inflammation processes and scar formation, such as selectin L (SELL) and the damage-specific DNA binding protein 2 (DDB2) were found to increase the risk of acne development [55]. In another study including 1893 severe acne cases and 5132 controls from the United Kingdom, 7.3 million SNPS were tested in a GWAS [56]. Three genome-wide significant loci (11q13.1, 5q11.2 and 1q41) containing genes linked to the transforming growth factor- $\beta$ (TGFb) cell signalling pathway, namely OVOL1, FST and TGFB2 were discovered [56]. To date, there have been no data about the effect of GHRL polymorphisms on the development of post-adolescent acne in the literature. Interestingly, we demonstrated that the prevalence of rs27647 polymorphism GA phenotype was significantly higher in acne patients and found that individuals carrying the GA and GG genotype of GHRL rs27647polymorphism demonstrated an increased acne vulgaris risk. The risk of acne vulgaris was more than 11,156 times higher in individuals with the GA genotype and 5,312 times higher in individuals with the GG geno- type compared to the AA genotype. Patients with rs27647 polymorphism AA genotype had significantly lower GAGS score than other genotypes, but no significant effect of these GHRL polymorphisms on metabolic parameters, insulin sensitivity markers and ghrelin levels was found in patients with acne vulgaris.

\section{Conclusions}

Our study shows that post-adolescent male patients with acne vulgaris had similar insulin sensitivity parameters but significantly lower ghrelin levels compared to healthy subjects. As a potent anti-inflammatory and anti-microbial peptide in hair follicles and sebaceous glands of the human skin, decrease in ghrelin levels may have a major role in the pathogenesis of acne vulgaris. Moreover, we reported for the first time that GA and GG genotypes of GHRL gene rs27647 polymorphism are associated with an increased risk of acne vulgaris development and the severity of acne in post-adolescent male patients. Further, large population based studies are needed to elucidate the role of ghrelin and GHRL polymorphisms in the pathogenesis of acne vulgaris.

\section{Conflict of interest}

The authors declare no conflict of interest.

\section{References}

1. Burris J, Rietkerk W, Woolf K. Acne: the role of medical nutrition therapy. J Acad Nutr Diet 2013; 113: 416-30.

2. Çerman AA, Aktaş E, Altunay ik, et al. Dietary glycemic factors, insulin resistance, and adiponectin levels in acne vulgaris. J Am Acad Dermatol 2016; 75: 155-62.

3. Ju Q, Tao T, Hu T, et al. Sex hormones and acne. Clin Dermatol 2017; 35: 130-7.

4. Bhate K, Williams HC. Epidemiology of acne vulgaris. $\mathrm{Br}$ J Dermatol 2013; 168: 474-85.

5. Di Landro A, Cazzaniga S, Cusano F, et al. Adult female acne and associated risk factors: results of a multicenter casecontrol study in Italy. J Am Acad Dermatol 2016; 75: 1134$41 e 1$.

6. Rahaman SMA, De D, Handa S, et al. Association of insulinlike growth factor (IGF)-1 gene polymorphisms with plasma levels of IGF-1 and acne severity. J Am Acad Dermatol 2016; 75: 768-73.

7. Napolitano M, Megna M, Monfrecola G, Insulin resistance and skin diseases. Sci World J 2015; 2015: 479354.

8. Kariya Y, Moriya T, Suzuki T, et al. Sex steroid hormone receptors in human skin appendage and its neoplasms. Endocr J 2005; 52: 317-25.

9. Azmahani A, Nakamura Y, Felizola SJ, et al. Steroidogenic enzymes, their related transcription factors and nuclear receptors in human sebaceous glands under normal and pathological conditions. J Steroid Biochem Mol Biol 2014; 144: 268-79.

10. Zouboulis CC. The human skin as a hormone target and an endocrine gland. Hormones 2004; 3: 9-26.

11. Spencer EH, Ferdowsian HR, Barnard ND, Diet and acne: a review of the evidence. Int J Dermatol 2009; 48: 339-47. 
12. Danby FW. Nutrition and acne. Clin Dermatol 2010; 28: 598604.

13. Melnik BC, Schmitz G. Role of insulin, insulin-like growth factor-1, hyperglycaemic food and milk consumption in the pathogenesis of acne vulgaris. Exp Dermatol 2009; 18: 833-41.

14. Chen W, Obermayer-Pietsch B, Hong JB, et al. Acne-associated syndromes: models for better understanding of acne pathogenesis. J Eur Acad Dermatol Venereol 2011; 25: 637-46.

15. Kojima M, Kangawa K. Ghrelin: structure and function. Physiol Rev 2005; 85: 495-522.

16. Tschöp M, Weyer C, Tataranni PA, et al. Circulating ghrelin levels are decreased in human obesity. Diabetes 2001; 50: 707-9.

17. Barreiro ML, Gaytán F, Caminos JE, et al. Cellular location and hormonal regulation of ghrelin expression in rat testis. Biol Reprod 2002; 67: 1768-76.

18. Ukkola O, Poykko SM, Antero Kesaniemi Y. Low plasma ghrelin concentration is an indicator of the metabolic syndrome. Ann Med 2006; 38: 274-9.

19. Nogueiras R, Perez-Tilve D, Wortley KE, et al. Growth hormone secretagogue (ghrelin-) receptors: a complex drug target for the regulation of body weight. CNS Neurol Disord Drug Targets 2006; 5: 335-43.

20. Deng B, Fang F, Yang T, et al. Ghrelin inhibits Angllinduced expression of TNF-alpha, IL-8, MCP-1 in human umbilical vein endothelial cells. Int J Clin Exp Med 2015; 8 : 579-88.

21. Cicek D, Demir B, Erder I, et al. Ghrelin in the pilosebaceous unit: alteration of ghrelin in patients with acne vulgaris. Eur J Dermatol 2015; 25: 323-8.

22. Ozuguz P, Kacar SD, Asik G, et al. Evaluation of leptin, adiponectin, and ghrelin levels in patients with acne vulgaris. Hum Exp Toxicol 2017; 36: 3-7.

23. Cemil BC, Ayvaz HH, Ozturk G, et al. Effects of isotretinoin on body mass index, serum adiponectin, leptin, and ghrelin levels in acne vulgaris patients. Adv Dermatol Allergol 2016; 33: 294-9.

24. Motawi TK, Shaker OG, Ismail MF, et al. Genetic variants associated with the progression of hepatocellular carcinoma in hepatitis C Egyptian patients. Gene 2013; 527: 516-20.

25. Ukkola O, Ravussin E, Jacobson P, et al. Mutations in the preproghrelin/ghrelin gene associated with obesity in humans. J Clin Endocrinol Metab 2001; 86: 3996-9.

26. Takezawa J, Yamada K, Morita A, et al. Preproghrelin gene polymorphisms in obese Japanese: association with diabetes mellitus in men and with metabolic syndrome parameters in women. Obes Res Clin Pract 2009; 3: 179-91.

27. Xu LL, Xiang HD, Qiu CC, et al. Association of ghrelin polymorphisms with metabolic syndrome in Han Nationality Chinese. Biomed Environ Sci 2008; 21: 188-92.

28. Liao N, Xie ZK, Huang J, et al. Association between the ghrelin Leu72Met polymorphism and type 2 diabetes risk: a meta-analysis. Gene 2013; 517: 179-83.

29. Dossus L, McKay JD, Canzian F, et al. Polymorphisms of genes coding for ghrelin and its receptor in relation to anthropometry, circulating levels of IGF-I and IGFBP-3, and breast cancer risk: a case-control study nested within the European Prospective Investigation into Cancer and Nutrition (EPIC). Carcinogenesis 2008; 29: 1360-6.

30. Cappel M, Mauger D, Thiboutot D. Correlation between serum levels of insulin-like growth factor 1, dehydroepiandrosterone sulfate, and dihydrotestosterone and acne lesion counts in adult women. Arch Dermatol 2005; 141: 333-8.
31. Nagpal M, De D, Handa S, et al. Insulin resistance and metabolic syndrome in young men with acne. JAMA Dermatol 2016; 152: 399-404.

32. Del Prete M, Mauriello MC, Faggiano A, et al. Insulin resistance and acne: a new risk factor for men? Endocrine 2012; 42: 555-60.

33. Doshi A, Zaheer A, Stiller MJ. A comparison of current acne grading systems and proposal of a novel system. Int J Dermatol 1997; 36: 416-8.

34. Friedewald WT, Levy RI, Fredrickson DS, Estimation of the concentration of low-density lipoprotein cholesterol in plasma, without use of the preparative ultracentrifuge. Clin Chem 1972; 18: 499-502.

35. Sultan C, Oliel V, Audran F, et al. Free and total plasma testosterone in men and women with acne. Acta Derm Venereol 1986; 66: 301-4.

36. Levell MJ, Cawood ML, Burke B, et al. Acne is not associated with abnormal plasma androgens. Br J Dermatol 1989; 120: 649-54.

37. Krause W. Serum levels of gonadotrophins, testosterone and estradiol in acne vulgaris. Hautarzt 1977; 28: 368-70.

38. Saleh BO. Role of growth hormone and insulin-like growth factor-l in hyperandrogenism and the severity of acne vulgaris in young males. Saudi Med J 2012; 33: 1196-200.

39. Kurzen H, Kurokawa I, Jemec GB, et al. What causes hidradenitis suppurativa? Exp Dermatol 2008; 17: 455-6.

40. Shlyankevich J, Chen AJ, Kim GE, et al. Hidradenitis suppurativa is a systemic disease with substantial comorbidity burden: a chart-verified case-control analysis. J Am Acad Dermatol 2014; 71: 1144-50.

41. Miller IM. Co-morbidities in inflammatory dermatological diseases. Psoriasis, hidradenitis suppurativa, and cardiovascular risk factors. Dan Med J 2015; 62: B5143.

42. Shalom G, Freud T, Harman-Boehm I, et al. Hidradenitis suppurativa and metabolic syndrome: a comparative crosssectional study of 3207 patients. Br J Dermatol 2015; 173: 464-70.

43. Miller IM, Ellervik C, Vinding GR, et al. Association of metabolic syndrome and hidradenitis suppurativa. JAMA Dermatol 2014; 150: 1273-80.

44. Balta I, Ekiz O, Ozuguz P, et al. Insulin resistance in patients with post-adolescent acne. Int J Dermatol 2015; 54: 662-6.

45. Kaymak Y, Adisen E, Ilter N, et al. Dietary glycemic index and glucose, insulin, insulin-like growth factor-l, insulin-like growth factor binding protein 3, and leptin levels in patients with acne. J Am Acad Dermatol 2007; 57: 819-23.

46. Cetinözman F, Aksoy DY, Elçin G, et al. Insulin sensitivity, androgens and isotretinoin therapy in women with severe acne. J Dermatolog Treat 2014; 25: 119-22.

47. Pöykkö SM, Kellokoski E, Hörkkö S, et al. Low plasma ghrelin is associated with insulin resistance, hypertension, and the prevalence of type 2 diabetes. Diabetes 2003; 52: 2546-53.

48. Pagotto U, Gambineri A, Vicennati V, et al. Plasma ghrelin, obesity, and the polycystic ovary syndrome: correlation with insulin resistance and androgen levels. J Clin Endocrinol Metab 2002; 87: 5625-9.

49. Schöfl C, Horn R, Schill T, et al. Circulating ghrelin levels in patients with polycystic ovary syndrome. J Clin Endocrinol Metab 2002; 87: 4607-10.

50. Min C, Ohta K, Kajiya M, et al. The antimicrobial activity of the appetite peptide hormone ghrelin. Peptides 2012; 36: 151-6.

51. Shaheen B, Gonzalez M, Acne sans P. acnes. J Eur Acad Dermatol Venereol 2013; 27: 1-10. 
52. Mora M, Adam V, Palomera E, et al. Ghrelin gene variants influence on metabolic syndrome components in aged spanish population. PLoS One 2015; 10: e0136931.

53. Gueorguiev M, Lecoeur C, Meyre D, et al. Association studies on ghrelin and ghrelin receptor gene polymorphisms with obesity. Obesity 2009; 17: 745-54.

54. Zavarella S, Petrone A, Zampetti S, et al. A new variation in the promoter region, the $-604 \mathrm{C}>\mathrm{T}$, and the Leu72Met polymorphism of the ghrelin gene are associated with protection to insulin resistance. Int J Obes 2008; 32: 663-8.

55. He L, Wu WJ, Yang JK, et al. Two new susceptibility loci $1 q 24.2$ and 11p11.2 confer risk to severe acne. Nat Commun 2014; 5: 2870

56. Navarini AA, Simpson MA, Weale M, et al. Genome-wide association study identifies three novel susceptibility loci for severe acne vulgaris. Nat Commun 2014; 5: 4020. 